Seale C. (2010) How the mass media report social statistics: a case study concerning research on end-of-life decisions. Social Science and Medicine 71, 5: 861-868

\title{
How the mass media report social statistics: a case study concerning research on end-of-life decisions
}

\begin{abstract}
The issue of whether it is right to be concerned about the accuracy with which mass media report social scientific research is explored through a detailed case study of media reporting of two surveys of UK doctors' end-of-life decision-making. Data include press releases, emails and field notes taken during periods of media interest supplemented by a collection of print and broadcast media reports. The case study contributes to existing knowledge about the ways in which mass media establish, exaggerate and otherwise distort the meaning of statistical findings. Journalists ignored findings that did not fit into existing media interest in the 'assisted dying' story and were subject to pressure from interest groups concerned to promote their own interpretations and viewpoints. Rogue statistics mutated as they were set loose from their original research report context and were 'laundered' as they passed from one media report to another. Yet media accounts of the research, fuelling an already heated public debate about ethical issues in end-of-life care, arguably acted as a conduit for introducing new considerations into this debate, such as the role played by sedation at the end of life, the extent to which euthanasia is practiced outside the law, and the extent of medical opposition to the legalisation of assisted dying. The expectation that accuracy and comprehensiveness should be the sole criteria for judging journalists' reports is, finally, considered to be unrealistic and it is argued that
\end{abstract}


social scientists need to understand and adapt to the conditions under which mass media reporting operates if they are to succeed in introducing the findings of social research into public debates.

Mass media are important influences on the public understanding of science, medical practice and ethical controversies in health care. There are long-standing concerns about the accuracy of media reporting of science (Nelkin, 1995, Signorielli, 1993) and in some instances reports have impinged deleteriously on the public health interest (for example, the impact of media reporting of the study done by Wakefield, Murch, Anthony, Linnell, Casson, Malik et al (1998) on MMR vaccine uptake (Lewis \& Speers, 2003), so that in the UK the Science Media Centre (www.sciencemediacentre.org), has been established to promote the messages of the science community in the media, sometimes with considerable success (Williams, Gajevic \& Kitzinger 2009). The impact of mass media reporting on public trust in the medical profession has been the theme in some research (for example, Entwistle \& Sheldon, 1999), suggesting that media have played a prominent role in questioning the cultural authority of doctors and medical knowledge.

This paper focuses on media reporting of ethical controversies in end-of-life care, focusing particularly on the reporting of two statistical studies of end-of-life decisions and medical attitudes towards assisted dying in the UK (Seale, 2006a, b; 2009 a, b, c; 2010). Before discussing this, some observations will be made about media reporting of statistical information, news values and mass media health coverage, focusing on what is known about the reporting of ethical issues in end-of-life care. 


\section{Statistics, news values and accuracy}

Journalists perceive quantitative research studies to be particularly reliable and newsworthy, and more so than qualitative methods (Schmierbach, 2005). The characteristic patterns of the reporting of statistics have been studied by a number of media analysts. Best $(2001,2004)$ presents a series of case studies of the way in which mass media report statistics so that social problems are constructed and sustained. He argues (Best, 2008) that only by understanding certain regular ways in which journalists behave, and thereby improving quantitative literacy, can the general public occupy an informed and appropriately critical view of statistical data relating to public issues.

Best (2001) identifies 'number laundering' as a key feature of media reporting of statistics. Here, a number appearing in one news report becomes a source for everyone interested in the social problem it describes: "Its origins as someone's best guess are now forgotten and, through repetition, it comes to be treated as a straightforward fact" (2001: 35$)$. Thus the number of 'stalkers' in the USA became established as 200,000 on the basis of an original guesstimate appearing in a news magazine. 'Hiding the measurement device' is another common phenomenon, illustrated by news reports of the number of 'bullies' (said to be $30 \%$ of the US school population), based on a study reported in the Journal of the American Medical Association whose methodology ensured a high count, but which news reports did not explain. 
Memorably, Best also describes the production of 'mutant statistics', whereby the meaning of numbers is 'stretched, twisted, distorted, or mangled' (2001: 62). One example is the estimate that 150,000 women in the USA are anorexic, a statistic originally promoted by activists seeking to draw attention to the problem. Someone, somewhere, changed this to say 150,000 women died from anorexia per annum, and this number became stuck in the journalistic imagination, being repeated across numerous influential books and articles (and websites: try typing '150,000 women anorexia' into Google). Significantly, for the case study reported in the present paper, Best observes: 'Mutant statistics often prove to be long-lived' (2001: 71)

Commissioning and publicising opinion polls is a way in which social movements often seek to generate public support (McInerney, 2000). This is not necessarily because the poll results always demonstrate public support for the social movement (although public support for the legalisation of assisted dying is high in the UK), but because the poll question itself sets the terms for a debate, meaning that if a person does not think in the way in which the question requires (for example, that the most important question about dying is whether assisted dying ought to be legalised) that person is then excluded. As McInerney writes:

the very act of engaging with a poll question - be that as a polled individual or as one reading the reports of opinion polls in the media or elsewhere - requires that that question become 'thinkable'...to engage with a poll, and respond to its framing of events, is itself a form of action. (2000:145) 
In this respect, McInerney is in agreement with qualitative social researchers who argue that fixed-choice questions impose particular ways of thinking about experience (Cicourel, 1964). Osborne and Rose (1999) elaborate a constructionist epistemological position further, arguing that such social scientific methods as opinion polls, 'create their phenomena through the procedures that are established to discover them' (1999: 367). Of course, constructionist epistemology can be applied to media reports themselves: is a concern with the 'accuracy' of media reporting of statistics the only legitimate response we may have? A constructionist view of media texts suggests other criteria for assessing the adequacy of reporting may be more appropriate. This issue will be returned to towards the end of this paper

Clearly journalists work under very different conditions from scientists, being obliged to generate stories quickly and express them briefly, producing a pressure to simplify and exaggerate that underlies the general features of reporting that authors like Best have described. Here, an understanding of journalistic news values - the criteria for deciding whether something is a 'story' - is helpful. Journalists - particularly 'tabloid' journalists - prefer dramatic stories which can be illustrated via personal accounts ('personalised') in which issues are often simplified and polarised (Sparks \& Tulloch, 2000; Fenton, Bryman, Deacon \& Birmingham, 1997). The classic account of news values is presented by Galtung and Ruge (1973) who note that a story will be more likely to make the news if it is negative, recent, close to home, compatible with dominant stereotypes, unambiguous, novel or unexpected, superlative (for example, the biggest, most destructive, most dangerous), relevant to an audience's daily life experience, personalised, involves important people or sources, or contains certain kinds of hard facts such as places, numbers and names. 
Other authors have noted additional characteristics that contribute to newsworthiness. Bell (1991), for example, notes that once a story is in the news there can be a 'feeding frenzy' whereby further instances of the same or similar things begin to be picked up and noticed by journalists. Boyce (2007) describes the related phenomenon of "pack journalism', evident in coverage of the MMR vaccine controversy, whereby journalists anxious not to miss out on what their competitors are getting, copy each others' reporting practices. Kitzinger $(1999,2000)$ notes the preference in health reporting for strong claims and certainty over tentative findings and equivocation, as well as the impact of pre-existing news 'templates' which provide journalists with a stock of standard story forms (for example, 'another child abuse story', 'another motorway pile-up story') into which new events can be fitted.

Harcup and O'Neill (2001) note that 'magnitude' (in terms of the number of people involved or the size of the impact) is an important news value, providing an insight into why large numbers are often preferred to small ones. These authors also mention 'surprise' as important, a theme also developed by Langer (1998) who notes that the taste amongst tabloid journalists for this is served particularly well when something intended to achieve one end (for example, a safety barrier) turns out (surprise, surprise!) to have the opposite effect (car driver is impaled on safety barrier!). Doctors, of course, are 'supposed' to save lives in the popular imagination, so clearly it may be particularly exciting to imagine them doing the opposite.

\section{Media reporting of assisted dying}


Both the American and British press largely present voluntary euthanasia sympathetically, particularly if 'terminal illness' is deemed to be present (Pollock and Yulis, 2004; Hausmann, 2004). This is because the vehicle for a report is very commonly the story of a particular case in which the sympathies of the reader are engaged (thus, the issues are 'personalised'). Reports tend to focus on individuals who want to end their lives by euthanasia or assisted dying as these present the opportunity to tell a story of an individual battling against the odds.

McInerney's $(2006,2007)$ studies of Australian press reports take this analysis further. She observes that social movements, such as the 'requested death' movement that campaign for the legalisation of assisted dying, are able to use media messages to 'construct' an issue more easily when the general public have little knowledge or experience of the matter at hand. And the dying process, as many commentators have observed, is relatively hidden from view in modern societies (Gorer, 1965; Bauman, 1992; Mellor \& Shilling, 1993).

A degree of voyeurism is involved in press reporting of serious and terminal illness, and this too requires personal stories about dying people rather than dry outlines of general ethical debates. The prominence of particular personal accounts then encourages readers to believe that these are typical of all such experiences, particularly if the accounts all have a similar structure and overall message (such as media coverage of the procession of individuals travelling from the UK to Dignitas in Switzerland for assistance in their suicides). Journalists like to show ordinary people behaving like heroes, or being 'victims' in need of rescue, in this case from the 
deterioration of their own bodies and from those who will not accede to requests for assisted dying, who are thereby constituted as 'villains' (Seale, 2002).

The case study reported here concerns a statistical study about controversial end-oflife issues. By providing information about how media reporting transformed the messages of the original social scientific report, it is hoped that some general conclusions about the relationship between social science and the media may be drawn.

\section{Method}

This study draws on notes made by myself (CS) at the time as I participated in the events described, as well as other documentary sources. In several respects, the method of this study uses an approach similar to that reported by Deacon, Fenton $\&$ Bryman (1999) in their account of the natural history of a news item, in which they traced the production, coverage and reception of a news story about a research study reporting an investigation into the controversial topic of False Memory Syndrome, with the exception that the present study reports on a wide range of media coverage of several linked research reports.

As research investigator on the studies, I have access to the original reports and questionnaires used in the research studies on end-of-life care, and to press releases about the results and emails relating to these. Newspaper coverage of these studies was tracked through Nexis, a database of worldwide English-language newspapers (www.lexis/nexis.com/nexis) and Google was used to track online coverage.

Television and radio reports were recorded. The media documents analysed for this 
report, then, comprised 37 national and 40 local newspaper articles, 10 reports in professional media (such as the news section of the British Medical Journal, or Pulse magazine), 5 reports in general magazines (such as the Economist or the Christian Herald), 11 radio and 4 television reports, and 31 web site articles. In addition, 7 press releases and 35 emails were included in the data set.

This material has been read and inspected closely, with a view to identifying the various ways in which news reporting of these studies was carried out, focusing on examples which demonstrate marked departures from the original messages of the research reports. A comparison is made between the key messages of the original research reports and the findings emphasised or ignored by media reports.

\section{Results}

The first survey: prevalence of end-of-life decisions

This was reported in two papers appearing in the journal Palliative Medicine in 2006 (Seale 2006a, b), resulting from a postal survey of doctors. The first report concerned how many people in the UK died from euthanasia or physician assisted suicide, as well as how many other end-of-life decisions occurred, comparing this with results from similar surveys in other countries. The second report concerned the extent to which end-of-life decisions were discussed between doctors, patients and others, and how this compared with other countries. Survey questions replicated those used in other studies (van der Maas, Delden, Pijnenborg \& Looman, 1991; van der Heide, Deliens, Faisst, Nilstun, Norup, Paci et al, 2003) but the method for sampling deaths differed from Dutch and other European surveys (though was the same as an Australian survey reported by Kuhse, Singer, Baume, Clark, \& Rickard (1997) which 
used the same questions), introducing the possibility of sampling bias. The response rate was $53 \%$.

The study was done from Brunel University, West London, where the author was appointed as professor of sociology. At the time, Brunel employed a freelance public relations firm to generate publicity for the research studies published by Brunel staff. In consultation with this firm, the author prepared a press release containing the following information:

The doctors' replies were used to estimate the proportion of UK deaths where particular end-of-life decisions were made. The proportion of UK deaths involving an end-of-life decision were:

(1) voluntary euthanasia $0.16 \%$

(2) physician-assisted suicide $\mathbf{0 . 0 0 \%}$

(3) ending of life without an explicit request from patient $0.33 \%$

(4) alleviation of symptoms with possibly life shortening effect $32.8 \%$

(5) 'non-treatment' decisions

(eg: withholding or withdrawing treatment)

$30.3 \%$

Once finalised, a journalist in the Guardian newspaper (a 'broadsheet' or 'serious' newspaper with a highly educated readership) was sent the press release on the understanding that she would report the results on the $17^{\text {th }}$ January 2006 , the day before the information was released to other media, thus gaining an 'exclusive'. At the same time, the public relations firm sent the press release by email to several members of the Brunel senior management team, as was routinely done in advance of 
release. One of these recipients forwarded the email to a prominent campaigner for the legalisation of assisted dying who then sent it to the Voluntary Euthanasia Society (VES). Early in the morning of the $17^{\text {th }}$ VES sent their own press release by email to numerous journalists, stating:

NEARLY THREE THOUSAND PATIENTS HELPED TO DIE EVERY YEAR BY DOCTORS WHO BREAK THE LAW

FIRST EVER SURVEY UK-WIDE STUDY SHOWS FURTHER 200,000 PATIENTS HAVE DEATH ACCELERATED BY DOCTORS WITHOUT SAFEGUARDS AGAINST ABUSE

\footnotetext{
Anything up to 191,811 patients had their deaths accelerated by doctors using pain relief.
}

Thus, VES had calculated that adding $0.16 \%$ to $0.33 \%$ made $0.49 \%$, which as a proportion of all UK deaths was roughly 3,000 , and that $32.8 \%$ could be transformed into 'Anything up to 191,811 patients'.

As well as turning very small numbers such as 0.49 into much larger numbers ("nearly three thousand'), the transformation involved turning the answer 'yes' to the original question doctors were asked '[Did you take your decision] taking into account the probability or certainty that this action would hasten the end of the patient's life" or "partly with the intention of hastening the end of life?" into "HAVE DEATH ACCELERATED BY DOCTORS WITHOUT SAFEGUARDS AGAINST ABUSE.” 
This is an example of 'hiding the measurement device' (Best, 2001: 51). Note also that 'Anything up to 191,811 patients' is transformed even within this document into the larger number of '200,000 PATIENTS' in the headline.

Although the VES press release, then, represents a rhetorical inflation and distortion of the messages of the original paper (thus, in Best's (2001) terms, beginning the process of generating a 'mutant statistic') it can be seen to contain some features qualifying its message, in the form of the words 'Anything up to' and 'NEARLY' before the numerical estimates provided. These qualifications were not taken up in journalists' reports. The Daily Mail (a mid-market newspaper espousing socially conservative values and targeting a female readership) produced a front page headline:

DOCTORS 'HELP' 2 IN 3 TO DIE; Survey fuels debate over medical intervention in patient deaths (Daily Mail: January $18^{\text {th }} 2006$ )

The report continued with:

Around 180,000 patients a year, or one third, die after doctors decide to withdraw or refuse them treatment, the research suggested.

...Another third of deaths involve a doctor giving pain relief to a patient in a way which shortens their life....

...nearly as many deaths were caused by what the study called 'non-treatment decisions' which involve withholding or withdrawing treatment. (Daily Mail: January $18^{\text {th }} 2006$ ) 
As a further twist, an interest group asked for a comment by the Daily Mail journalist presented an extreme interpretation of the reality that was imagined to lie behind the statistics, made possible because information about the original measuring device had become hidden:

... SOS NHS Patients in Danger, a group formed by families of patients who died after withdrawal of treatment without the consent of relatives. It said the figures exposed 'outrageous torture and elimination of the elderly'. (Daily Mail: January $\left.18^{\text {th }} 2006\right)$

Two weeks later the same newspaper reported that:

research showed two in three patient deaths are now caused by medical intervention. (Daily Mail: January $30^{\text {th }}$ 2006)

In Best's (2001) terms, this represents an early step in the 'number laundering' process, whereby a statistic's origin becomes forgotten as its repetition establishes it as a 'straightforward fact' in the public imagination. In addition, this report contained example of straightforward fabrication:

The survey of doctors, compiled by the respected Brunel University, said half of these deaths fall into the category of 'withdrawal of treatment', including the highly controversial withholding of food and water. (Daily Mail: January $30^{\text {th }} 2006$ ) 
In fact, no data was collected or reported in this survey on what kinds of treatment were withdrawn, so the statement about food and water is a figment of the journalist's imagination. The view that Brunel is a 'respected' university might also be regarded as a dubious judgement by those who have never heard of this university, or who note its middling to low position in national and international league tables, so here represents an additional rhetorical exaggeration.

The Daily Mail is a newspaper with a reputation for sensationalised reporting of this sort, but the Guardian has a reputation as a 'serious' paper that presents more balanced views. The Guardian journalist who was originally offered the 'exclusive' was placed in a less commanding position by the VES press release. She spoke with the author of the report and told him that, unfortunately, she would be obliged to follow the lead provided by the VES rather than following the Brunel release. The headline in this paper stated 'Euthanasia doctors aid 3,000 deaths: First UK study provokes furore' (Guardian: January $\left.18^{\text {th }} 2006\right)$.

Other newspapers, broadcast media and web sites followed this story in similar terms, with reporting being largely confined to the UK press, but with short reports in some American and Australian newspapers. Two and a half years later, the following comment appeared in a column written by Simon Jenkins in the Guardian, indicating that the 'number laundering' process had established this statistic as factual for some people: 
The law of death is a shambles. A leading authority on euthanasia, Professor Emily Jackson of the LSE, began a recent lecture on the subject with the sensational question: "What is the most common cause of death in Britain?" Her answer was "death by killing". And who does the killing? "Doctors." One third of all registered deaths are by deliberate morphine overdose and one third by the removal of life support, premeditated acts by medical staff. (Guardian: 22 October 2008

It would be fair to say that journalists are not the only people involved in changing the meaning of the statistics reported in the study. Jackson (2007), writing for an academic audience, initially reports the survey in a way that is suitably inconclusive about the causal impact of medical actions: 'Roughly a third of all deaths...follow treatment withdrawal' (2007: 49) but subsequently loses her inhibitions about causation: 'death is caused by treatment withdrawal...in around a third of all deaths in the United Kingdom' (2007:57; my italics). Later we shall see that a similar transformation was effected by journalists in relation to the role of sedative drugs.

\section{Medical attitudes towards legislative change}

The first survey also contained two questions about the doctor's views on whether a change of law would have helped the respondent in caring for the particular patient on whose care they were reporting. The questions were worded as follows:

(i) Did your perception of the law, as it applies in the UK, inhibit or interfere with your preferred management of the patient and end of life decision? Yes/No 
(ii) (If yes to (i)) Would enactment of laws providing defined circumstances in which a drug may be prescribed and/or administered to patients with a terminal illness, with the explicit purpose of hastening the end of life, have enabled your patient to receive better and more appropriate care? Yes/No

Note that these are questions about the relevance of legal change for that particular patient, not questions about the general desirability of legal change. As reported in the research paper, $4.6 \%$ of doctors said 'yes' to the first question, and $2.6 \%$ said 'yes' to the second one. The Brunel university press release reported the findings on medical attitudes as follows:

A small proportion of doctors felt UK law had inhibited or interfered with their preferred management of the patient on whose care they reported $(4.6 \%$ (3.1-6.1\%) of doctors) or that a new law would have facilitated better management of that patient (2.6\% (1.4-3.8\%) of doctors).

51 doctors wrote comments on the questionnaires containing views about the desirability of legal change or of medical involvement in hastening death. The majority of these (82\%) indicated support for the current legal ban on medical involvement in euthanasia or assisted suicide.

On this occasion, reporters and commentators from lobbying organisations took differing positions on what was being claimed, but in no case was the finding reported accurately: 
this excellent and important piece of research... found more than 97 per cent of doctors were against a change in the law. David Praill, Chief Executive, Help the Hospices. (Letter to the editor; The Times: January 23, 2006)

HEADLINE: Doctors snub euthanasia Euthanasia...has almost no support among doctors, a new study reveals. The survey of 857 GPs and hospital doctors found...only 2.2 per cent supported a change in the law. (Pulse: January 19, 2006)

just two per cent think euthanasia should be made legal. (Sun: January 18, 2006)

These quotes are taken from publications with a wide variety of agendas. The Times, of course, is a widely respected 'broadsheet' newspaper read predominantly by those in higher socio-economic categories; The Sun is the UK's most popular 'tabloid', read predominantly by males and people in lower socio-economic categories. Pulse is a magazine aimed at general practitioners or family doctors.

The second survey (response rate 42\%) used four questions taken from the British Social Attitudes survey to compare the opinions of the medical population directly with the opinions of the general public. To avoid a lengthy repetition of the results here, the summary provided in the press release, issued by the funders and sponsors of the study is given below: 


\section{Majority of UK doctors opposed to legalisation of euthanasia}

Two-thirds of UK doctors are opposed to the legalisation of euthanasia and physician-assisted suicide, according to research published today in Palliative Medicine.

A change in the law to legalise euthanasia is supported by $34 \%$ of doctors (general public: $82 \%$ ), with $35 \%$ backing physician-assisted suicide (general public: 62\%). The questions mirror those asked in the British Social Attitudes survey in 2007, making this the first direct comparison between members of the public and doctors.

As with the first survey, journalists' reports differed, with some emphasising the proportion of doctors who opposed, and others the proportion who supported a change of law:

HEADLINE: DOCS VETO RIGHT TO DIE

TWO-THIRDS of UK doctors oppose euthanasia and medically assisted suicide. (Daily Record: March 25, 2009; a Scottish popular tabloid)

\section{HEADLINE: MAJORITY OF DOCS AGAINST EUTHANASIA LAW}

TWO thirds of doctors are against the legalisation of euthanasia and physician assisted suicide, a poll claims. (Mirror: March 25, 2009; a left-leaning tabloid) 
HEADLINE: Euthanasia wins support of one in three doctors

ONE in three doctors supported a change in the law to legalise euthanasia, a new study showed. (Daily Telegraph: March 25, 2009; a conservative broadsheet newspaper)

HEADLINE: 1 in 3 GPs would help terminally ill die

A THIRD of doctors would help terminally ill patients die with a lethal dose of drugs, it was revealed today. (Evening Standard: March 24th, 2009; a London evening paper)

Here, then, we see in the case of the first survey a distortion of the true picture, as doctors in this survey had not been asked for their general views about the desirability of legal change, but their views were reported by journalists and others as if they had. Reporting of the second survey was more accurate, but the choice of which aspect of the statistic to report (support for legalisation or opposition) allowed individual journalists to present only a partial truth.

\section{Reporting findings about sedation}

The second survey asked doctors about their use of sedation, using a question taken from a translation of a Dutch survey which had reported in the British Medical Journal (Rietjens, van Delden, Onwuteaka-Philipsen, Buiting, van der Maas \& van der Heide, 2008). The question said: 
Was the patient continuously and deeply sedated or kept in a coma before death? Yes/No

The report of the study summarised the finding about the prevalence of this form of sedation in the following terms:

Table $1 \ldots$ shows the rate at which continuous deep sedation is given...The figure of $16.5 \%$ is high compared with those for other countries where the same question has been asked (in the Netherlands, for example, the question resulted in a figure of $8.2 \%$ in 2005; in Belgium, a similar question resulted in a figure of $8.3 \%$ in 2001). (Seale, 2009b: 201)

It was recognised that the figure of $16.5 \%$ was surprisingly high, and in the press release that accompanied the first reports from the study, this finding was not mentioned, as the funders (the National Council for Palliative Care and associated charities) wished to focus journalists' attention on other findings (notably, that which showed most doctors were opposed to the legalisation of assisted dying). Yet media reporting of the sedation findings occurred nevertheless and these demonstrate a gradual linguistic transformation of this finding into one in which the provision of sedative drugs comes to be seen as a cause of death.

The process began some months after the report was published, when a perceptive $\mathrm{BBC}$ radio journalist who had been present at the earlier press conference and had noticed in the research reports that the $16.5 \%$ figure for sedation was part of the findings of one of the papers ran a story about the use of sedation in palliative care. 
After interviewing the author he wrote in his summary of his radio message the following on the $\mathrm{BBC}$ website:

Research suggests use of CDS in Britain is particularly high - accounting for about one in six of all deaths. BBC web site 12/08/2009 (http://news.bbc.co.uk/1/hi/health/8184108.stm)

Clearly, the term 'accounting for' is different from the terminology of the original report ('rate at which [sedation] is given') and is potentially suggestive of a causative influence.

In early September that year, a letter from six prominent individuals, including two from the 'pro-life' organisations 'Choose Life' and the 'Medical Ethics Alliance' appeared in the conservative broadsheet newspaper, the Daily Telegraph, indicating concern about the possible over-use of sedation under the auspices of the Liverpool Care Pathway (LCP) in which it was stated:

It is disturbing that in the year 2007-2008, 16.5 per cent of deaths came about after terminal sedation. (Daily Telegraph: 3 September 2009)

The term 'came about after' is perhaps less open to causative inference than 'accounting for', but nevertheless retains this as a possible imputation. This can be seen if the following (imaginary) phrasing had been used in the letter: 
$16.5 \%$ of people who die in the UK are said by their doctors to have received continuous deep sedation until death.

But this is perhaps less attractive to those wishing to place a particular 'spin' on the results.

The Telegraph coverage led to a considerable amount of media reporting of the effects of the LCP on patient care. A few days after the Telegraph letter, it became clear that groups campaigning against the proposed reforms of American health care under President Obama had picked up on the story and were putting their own spin on it. The following quote comes from a website disseminating the views of Lyndon Larouche, an American anti-government political activist (relevant passage given in bold):

On Sept. 3, Britain's Daily Telegraph published a lead article featuring a Letter to the Editor from six prominent British doctors and health-care professionals, charging that large numbers of patients in the U.K. are being "sentenced to death," by means of involuntary euthanasia. The numbers were stunning: According to a report from a researcher at Barts and the London School of Medicine and Dentistry, one out of six people who died in the United Kingdom in 2007-08, died of continuous deep sedation, the mode of euthanasia which the doctors describe. As we present the evidence, you will see precisely what the Obama Administration has in store for the United States-in its full Nazi form. Executive Intelligence Review (web-based). Sep 11th, 2009. www.larouchepub.com 
The Executive Intelligence Review formulation for this finding is, of course, at the extreme end of the spectrum of causal language ('died of' and 'mode of euthanasia'), demonstrating the 'mutant statistic' phenomenon described by Best (2001) in stark form.

News values, media reporting and the research findings

A major emphasis of media reporting was, then, on the role of doctors in taking decisions that shorten life, this being a story that has high 'news value'. The story could be presented as a surprising reversal of what one would expect (Langer, 1998), as doctors - whose role it is to save lives - could be shown to be ending lives instead. The high profile of the coverage also reflected the particular authority of numbers for journalists (Schmierbach, 2005) and the mutation and number laundering processes described enabled the magnitude (Harcup and O’Neill, 2001) and certainty (Kitzinger, 1999) of the story to be increased. Stories about assisted dying, and of doctors becoming implicated in this, have been an ongoing feeding frenzy (Bell, 1991) in the British press in recent years, so the research reports provided additional fodder to satisfy this appetite.

A summary of the key messages of the original research reports is provided below, being the author's own answer to the question 'What has this research work achieved?'

The two surveys showed the following substantive things: 
1. Euthanasia and physician-assisted suicide is very rare in the UK (Seale 2006a, 2009b).

2. UK doctors make a lot of end-of-life decisions, so are actively managing their dying patients, perhaps more so than in some other countries where palliative care has not developed as far (Seale 2006b).

3. UK doctors are good at sharing end-of-life decisions with patients, relatives and medical colleagues (in spite of Britain being a 'non-permissive' country with regard to assisted dying) (Seale 2006b).

4. UK doctors are, on the whole, opposed to the legalisation of assisted dying (unlike the British general public) (Seale 2009a).

5. One in ten dying patients make requests for a hastened death and these sometimes persist in spite of the care provided. A high rate of such requests occur in palliative care (Seale 2009c).

6. Doctors' with religious or faith beliefs are less willing to carry out (or to say they carried out) actions that were partly intended to end life, or to provide continuous deep sedation until death (which raises issues of the relative balance being struck between sanctity of life and quality of life) (Seale 2009c, 2010).

7. There is a relatively high rate of use of continuous deep sedation until death in UK medical practice, which deserves further investigation (Seale 2009b, 2010).

8. Groups considered 'vulnerable' (older people, people in care homes, people with dementia) are no more likely than other patients to receive care from a doctor who thinks their decisions will have shortened life, or to receive 
continuous deep sedation until death (so that a 'slippery slope' does not appear to exist) (Seale 2009c, 2010).

Methodological gains are:

1. A better understanding of the sampling errors involved in the 'recall of last patient' method, when compared with sampling from death certificates (Seale 2006a, 2009b).

2. A better understanding of the role of question wording in inflating rates at which 'non treatment decisions' and 'double effect' decisions have been reported in numerous studies of other countries published in leading medical journals (Seale 2009b).

3. A better understanding of how overall rates of continuous deep sedation until death are inflated by the inclusion of deaths in intensive care settings (Seale 2010).

4. A baseline has been established for monitoring trends in end-of-life decisions over time.

Perhaps understandably, media reporting did not focus on the methodological gains. Instead, the main focus was on the topics referred to in items 1, 4 and 7 with a small amount of coverage of item 2 . Notably, items 1 and 4 relate directly to the debate about assisted dying. Although sedation (item 4) can be thought of as an appropriate medical treatment that has nothing to do with hastening death (Sykes and Thorne, 2003), the hastening death angle was emphasised by stressing that it was possible sedation was being used as an alternative to euthanasia. Clearly, then, coverage of this 
research study fitted an existing agenda for journalists, which was to understand research about end-of-life care as being largely relevant to the debate about whether assisted dying should be legalised. In this respect, the story was fitted into an existing 'template' (Kitzinger, 2000) for stories about end-of-life decisions.

The findings about sharing decisions (item 3) requests for a hastened death (item 5), religion (item 6), and the 'slippery slope' argument (item 8) were rarely reported in the media reports studied for this paper, and in some cases (items 5 and 8) not at all. Item 5 was highly newsworthy, having the potential for headlines such as 'ONE IN TEN ASK TO DIE' but this aspect of the findings was missed by journalists, perhaps because it was not prominent in press releases. The filtering effect implied by theories of 'news values' then, is not perfectly applied in practice.

Within the items that journalists focused on, there was considerable distortion of the main messages contained in the original research reports. For example, in reporting item 1 many journalists appear to have done their best to turn a very small number $(0.49 \%)$ into an apparently big number $(3,000)$ in order to produce an exaggerated effect. It occurred to no journalist to say that the figure might be questioned. After all, when hundreds of (presumably) busy doctors take time out to fill in a detailed form, might it be possible that a few of them ticked a box without properly reading the question?

Media reporting of item 2 has differed in emphasis from that of the original research report. The study author emphasised that the high rate of end-of-life decisions may be a sign that palliative care had had a positive influence on medical management of 
dying; yet this was interpreted by some journalists with such messages as “DOCTORS 'HELP' 2 IN 3 TO DIE” (Daily Mail: January 18 $\left.{ }^{\text {th }} 2006\right)$.

Media reporting of item 4 was inaccurate in the case of the first survey (perhaps partly because the implications of the wording of the question were hard to grasp on a superficial reading). In the case of the second survey, where things were much simpler, media reporting varied between those who believed the glass was two-thirds full, and those who believed it was one-third empty. This appears to have depended on the particular preference of the journalist about whether assisted dying ought to be allowed.

In relation to item 7 , it could be argued that the media message about the high rate of sedation was similar to that of the original research report, in that both author and journalists were in agreement that the high rate deserved further investigation. Unlike journalists, though, sedation was not interpreted by the original author as if it were a cause of death. And like many others in the academic and clinical communities, the author is still wondering what doctors thought the question about sedation meant when so many of them ticked the 'yes' box. This methodological thought did not, it seems, occur to any journalists. It certainly did not trouble the authors of Executive Intelligence Review.

\section{Discussion}

This case study has shown that news coverage of research on end-of-life issues has been highly selective, reporting being influenced by a combination of standard journalistic news values, and the activities of lobbying organisations such as the 
Voluntary Euthanasia Society, pro-life groups and representatives of the palliative care community. In various respects, the study has illustrated more general features of the way in which mass media report social statistics (Best 2001, 2004) and contribute to the social scientific construction of social problems (Osborne and Rose 1999). Numbers derived from the original research reports have been used to support arguments not contained in these original reports, and have contributed to new perceptions of 'the facts' that were not imagined or intended by the author of the studies. The study reminds us that the mass media is produced by people who pursue an agenda that tends towards sensationalism and who prefer polarisation of arguments, to produce dramatic effects (Fenton, Bryman, Deacon \& Birmingham, 1997). The effect of this is to generate a particular version of reality.

In the UK, it is currently proposed to evaluate the 'impact' of research done within universities, as an element in the Research Excellence Framework (REF) for 2013, an exercise which will determine the funding of universities. One indicator of impact is likely to be 'influence on public policy debate' and REF leaders regard this as being 'indicated by citations by non-government organisations or the media.' (www.hefce.ac.uk/research/ref/). Taking this crude indicator of impact, these studies (which cost $£ 5,585$ and $£ 46,566$ respectively) represent exceptional 'value for money’ since media coverage has been considerable. But one of the things illustrated by this case study is the way in which media-savvy lobbying organisations (in particular, the VES), were able to spin the findings in a way that appealed to news values, resulting in simplified and sensationalised coverage which dispensed with the more cautious approach to inference contained in the original research reports. It seems likely that the REF's linkage of funding decisions to high numbers of media citations will result 
in pressures on university press officers to engage in similar behaviour to that of lobbying organisations. The pressure on research workers to carry out studies that are likely to be of interest to the media, rather than reflecting the information needs of a particular scientific, policy or theoretical area, is also likely to increase. This contains the potential for distortion of the public image of social scientific reasoning, as it becomes less easily distinguishable from journalistic modes of argument.

The selective media reporting of results that has been described in this case study raises issues of whether a high volume of coverage is consistent with the broader REF objective of doing research whose impact delivers 'demonstrable benefits to the economy, society, public policy, culture and quality of life' (www.hefce.ac.uk/research/ref/). Of course, the judgement of whether media coverage of this research has made a positive contribution to public debates depends, in part, on where one stands on issues like the legalisation of assisted dying and other areas of controversy within end-of-life care. Given that media reporting of individual cases of 'mercy killing' and assisted suicide are, in general, reported in such a way that supports the case for legalising these practices (Hausmann, 2004; McInerney, $2006,2007)$ it might be seen as a corrective that much of the media coverage of this research has provided support for the opposite view.

This leads us to the consideration that even 'inaccurate' media stories can serve a valuable purpose. Kitzinger (1999) points out that judging media coverage by assessing the accuracy with which official or scientific information has been transmitted misses the point that the role of the media is largely to offer a forum for raising issues as matters for public debate. Scientific reports may act as a stimulus for 
this, as was arguably achieved by media coverage of the results concerning sedation, which up until that point had not been debated in the public arena to any great extent. It is, perhaps, naïve to be panicked by media sensationalism or inaccuracy as these are the techniques journalists use for generating public interest in debates and controversies. One does not have to adopt the constructionism of authors like Osborne and Rose (1999) to believe this, but instead accept 'inaccuracy' as almost inevitable. It is perhaps this acceptance that Fenton, Bryman, Deacon \& Birmingham (1998) had in mind when they argued for the view that social scientists need to adapt to the very different culture of journalism if they are to contribute to public debates.

Clearly, though, media reporting in this area is also influenced by the agendas of interest groups that try to draw journalists towards their own preferred messages. Some of the distortion of the original message reflected the success of particular organisations in exercising this influence. Anticipating the variety of possible 'spins' that may be placed on a controversial scientific report by other organisations is an important element in managing communications between social scientists and the media. It is hoped that the case study presented here will be of some assistance to future researchers and press officers designing approaches to releasing results of controversial studies to a wider public. 


\section{References}

Bauman, Z. (1992) Mortality, immortality and other life strategies .Cambridge: Polity Press.

Bell, A. (1991). The language of news media. Oxford: Blackwell.

Best, J. (2001). Damned lies and statistics: Untangling numbers from the media, politicians, and activists. Berkeley: University of California Press

Best, J. (2004). More damned lies and statistics: How numbers confuse public issues. Berkeley: University of California Press

Best, J. (2008). Beyond calculation: quantitative literacy and critical thinking about public issues. In B.L. Madison \& L.A. Steen (Eds.), Calculation vs. context: quantitative literacy and its implications for teacher education. (pp. 125-135) Washington DC: Mathematical Association of America

Boyce, T. (2007). Health, risk and news: The MMR vaccine and the media. London: Peter Lang

Cicourel, A. (1964). Method and measurement in sociology. New York: Free Press

Deacon, D., Fenton, N. \& Bryman, A. (1999). From inception to reception: the natural history of a news item. Media Culture \& Society, 21, 5-31. 
Entwistle, V. and Sheldon, T. (1999). The picture of health? Media coverage of the health service. In B. Franklin (ed.) Social policy, the media and misrepresentation. (pp. 118-134), London: Routledge.

Fenton, N., Bryman, A., Deacon, D. \& Birmingham, P. (1997). 'Sod off and find us a boffin': journalists and the social science conference. Sociological Review, 45, 1, 123.

Fenton, N., Bryman, A., Deacon, D. \& Birmingham, P. (1998). Mediating social science. London: Sage Publications.

Galtung, J. and Ruge, H.H. (1973). The structure of foreign news. Journal of Peace Research, 2, 1, 64-91.

Gorer, G. (1965) Death, grief and mourning. London: Cresset.

Harcup, T. and O'Neill, D. (2001). What is news? Galtung and Ruge revisited. Journalism Studies, 2, 2, 261-280

Hausmann, E. (2004). How press discourse justifies euthanasia Mortality, 9, 3, $206-$ 222. 
Jackson, E. (2007). Death, euthanasia and the medical profession. In Brooks-Gordon, B., Ebtehaj, F., Herring, J., Johnson, M. and Richards, M. (eds) Death rites and rights (pp. 37-55), Oxford and Portland, Oregon: Hart Publishing.

Kitzinger, J. (1999). Researching risk and the media. Health, Risk and Society 1,1 5569

Kitzinger, J. (2000). Media templates: patterns of association and the (re) construction of meaning over time. Media Culture and Society 22,1, 61-84.

Kuhse, H., Singer, P., Baume, P., Clark, M. \& Rickard, M. (1997) End-of-life decisions in Australian medical practice. Medical Journal of Australia 166, 191-6.

Langer, J. (1998). Tabloid television: popular journalism and the 'other news'. London: Routledge.

Lewis, J \& Speers T. (2003). Misleading media reporting? The MMR story. Nature Reviews Immunology 3, 913-918

McInerney, F. (2000). "Requested death": a new social movement. Social Science \& Medicine, 50, 137-154.

McInerney, F. (2006). Heroic frames: discursive constructions around the requested death movement in Australia in the late-1990s. Social Science \& Medicine, 62, 654667. 
McInerney F. (2007). Death and the body beautiful: Aesthetics and embodiment in press portrayals of requested death in Australia on the edge of the 21 st century. Health Sociology Review, 16, 5, 384-396.

Mellor, P.A. and Shilling, C. (1993). Modernity, self identity and the sequestration of death. Sociology, 27, 3, 411-431.

Nelkin, D. (1995). Selling science: how the press covers science and technology. New York: WH Freeman.

Osborne, T. \& Rose, N. (1999) Do the social sciences create phenomena? The example of public opinion research. British Journal of Sociology, 50,3, 367-396.

Pollock, J. \& Yulis, S. (2004). Nationwide newspaper coverage of physician-assisted suicide: a community structure approach. Journal of Health Communication, 9, 4, 281-307.

Rietjens, J., van Delden, J., Onwuteaka-Philipsen, B., Buiting, H., van der Maas, P. \&, van der Heide, A. (2008). Continuous deep sedation for patients nearing death in the Netherlands: descriptive study. British Medical Journal, 336, 810-813.

Schmierbach M. (2005). The influence of methodology on journalists' assessments of social science research. Science Communication, 26, 3, 269-287. 
Seale, C. (2002). Media and Health. London: Sage.

Seale, C. (2006a). National survey of end-of-life decisions made by UK medical practitioners. Palliative Medicine, 20, 1, 3-10.

Seale, C (2006b). Characteristics of end-of-life decisions: survey of UK medical practitioners. Palliative Medicine, 20,7, 653-659.

Seale, C. (2009a). Legalisation of euthanasia or physician-assisted suicide: survey of doctors' attitudes Palliative Medicine, 23, 3, 205-212.

Seale, C. (2009b). End-of-life decisions in the UK involving medical practitioners Palliative Medicine, 23, 3, 198-204.

Seale, C. (2009c). Hastening death in end-of-life care: a survey of doctors. Social Science and Medicine, 69, 11, 1659-1666.

Seale, C. (2010). Continuous deep sedation in UK medical practice: descriptive study. Journal of Pain and Symptom Management, 39,1, 44-53.

Signorielli, N. (1993). Mass media images and impact on health. Westport Connecticut: Greenwood Press.

Sparks, C. and Tulloch, J. (2000). Tabloid tales: global debates over media standards. London: Rowman and Littlefield. 
Sykes, N. \& Thorne, A. (2003). The use of opioids and sedatives at the end of life. Lancet Oncology, 4, 312-318.

van der Maas, P.J., Delden, J.J.M., Pijnenborg, L. \& Looman, C.W.N. (1991). Euthanasia and other medical decisions concerning the end of life. Lancet 338, 669-674.

van der Heide, A., Deliens, L., Faisst, K., Nilstun, T., Norup, M., Paci, E., van der Wal, G. \& van der Maas, P.J. (2003) End-of-life decision-making in six European countries: descriptive study. Lancet 362, 345-350.

Wakefield, A.J., Murch, S.H., Anthony, A., Linnell, J., Casson, D.M., Malik, M., Berelowitz, M., Dhillon, A.P., Thomson, M.A., Harvey, P., Valentine, A., Davies, S.E. \& Walker-Smith, J.A. (1998). Ileal-lymphoid-nodular hyperplasia, non-specific colitis, and pervasive developmental disorder in children. Lancet 351, 637-41.

Williams, A., Gajevic, S., \& Kitzinger, J. (2009). UK National Newspaper Coverage Hybrid Embryos: Source strategies and struggles. Report for the Medical Research Council, the Academy of Medical Sciences, the Wellcome Trust, and the Science Media Centre. www.cardiff.ac.uk/jomec/research/researchgroups/riskscienceandhealth/fundedproject s/hybridembryos.html Imass media reporting paper revised 2 